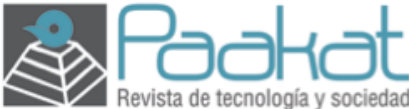

Paakat: Revista de Tecnología y Sociedad

e-ISSN: 2007-3607

Universidad de Guadalajara

Sistema de Universidad Virtual

México

suv.paakat@redudg.udg.mx

Año 10, número 18, marzo-agosto 2020

\title{
Recensión \\ Blockchain: aspectos tecnológicos, empresariales y legales
}

\author{
David López Jiménez* \\ ResearcherID: N-6460-2013 \\ EAE Business School, España
}

Obra reseñada: Ramón Vilarroig Moya y Carmen Pastor Sempere. (2018). Blockchain: aspectos tecnológicos, empresariales y legales. Navarra, España: Thomson Reuters Aranzadi.

[Recibido 05/02/2019. Aceptado para su publicación 10/03/2019]

DOI: http://dx.doi.org/10.32870/Pk.a10n18.421

La realidad pone de manifiesto que los recientes y disruptivos avances que acontecen en las nuevas tecnologías -que evolucionan cada vez a un ritmo más acusado- están incidiendo, de manera notable, en la forma en la que nos comunicamos, trabajamos o efectuamos actos propios del consumo. Asistimos, en estos escenarios y en otros muchos, a un cambio social sin precedentes. La sociedad $-y$, con ello, el sector público y el sector privado- se ve más influenciada por las tecnologías de la información y la comunicación (TIC). En este orden de cuestiones, podemos concluir que la digitalización que está protagonizando la sociedad está llamada a la consolidación de un nuevo orden en el que nos encontramos inmersos. Nos referimos a la sugerente estructura que se inicia con la cadena de bloques. El Blockchain, en efecto, se erige en una tecnología susceptible de impactar, de manera relevante, sobre los consumidores, o usuarios, y los empresarios. 
En un breve tiempo, sobre la base de dicha plataforma se acometerán, con cierta habitualidad y dinamismo, entre otras tareas, los denominados smart contrat o contratos inteligentes que, a pesar de su denominación, no son en sentido estricto contratos sino secuencias de códigos y datos únicamente. Referente a esto deben efectuarse algunas apreciaciones adicionales. En el smart contrat, aunque el pacto o acuerdo que se celebra entre las partes puede ser escrito o redactado en lenguaje humano, al menos un porcentaje del mismo será transcrito a un código de programación, que es una función autoejecutable.

En su contenido se incluyen las reglas y las consecuencias del contrato, y si bien, a diferencia de los contratos decimonónicos, el mecanismo de ejecución no estará supeditado a la voluntad de las partes sino a un programa que actuará de forma automática cuando identifique las reglas de ejecución, para que pueda cursarse la orden con respuesta automática, se debe poder programar un pago que se apoye en la cadena de bloques, abono que normalmente se hará en criptomonedas. Asimismo, los contratos inteligentes presentan numerosas prerrogativas.

En efecto, sus scripts pueden programarse en serie, de manera sencilla, al incorporarse en el Blockchain. Si se produce un evento desencadenante presente en el contrato, se remite la transacción a una determinada dirección. Superada la complejidad inherente a la programación, actúan con celeridad, de forma sencilla, inmodificable y, sobre todo, con una ejecución garantizada, ya que no permite el arrepentimiento (que no debe confundirse con el desistimiento). Naturalmente, los contratos inteligentes se crean habitualmente con el objetivo de producir efectos jurídicos, siempre y cuando se den las condiciones necesarias para su ejecución automática.

En los contratos legales inteligentes, como en cualquier otro contrato, las partes pueden pactar que la relación obligatoria esté sometida a una determinada condición. La valoración de la concurrencia de esta última se efectúa por parte de un tercero llamado oráculo; se trata de empresas externas, respecto a la cadena de bloques, que pueden facilitar al programa todo tipo de información y que han creado un software propio que les permite interaccionar con el smart contract. La actividad desarrollada por los oráculos, en su interacción con la cadena de bloques, es la de un tercero confiable e imparcial. Uno de los aspectos más sugerentes de los contratos inteligentes son las prestaciones pecuniarias que incorporan. Esta modalidad de contratos, del mismo modo que los ordinarios, concentra un sinalagma en el que al menos una de las prestaciones puede ser calificada como económica.

El problema estriba en que las diversas cadenas de bloques exigen que las transacciones económicas se efectúen en su propia criptodivisa. La más conocida es bitcoin (sin perjuicio de que hay otras muchas como ethereum, litecoin, ripple y dogecoin), que ha resultado no solo un medio de pago electrónico automatizable, sino también un instrumento de inversión especulativa y, además, de evasión fiscal y blanqueo de dinero. Gran parte de las operaciones de pago automatizado se efectúan por sistemas de criptodivis que, aunque estas últimas carecen de estatus legal reconocido, y tienen un mínimo de seguridad jurídica, son legales y admisibles. 
La aplicación de esta novedosa y prometedora tecnología a la vida cotidiana del usuario ha servido para que algunos recurrieran al Blockchain como una especie de revolución tecnológica, que se posiciona al mismo nivel que Internet. Se pronostica, por parte de algunos, que esta nueva tecnología desplazará a las autoridades decimonónicas de carácter centralizado, que, hasta ahora, han operado en muchos y variados campos, entre los que podemos referirnos a las comunicaciones y los negocios.

La monografía a la que nos referimos en la presente reseña, efectúa un examen, completo y multidisciplinar, de la tecnología de la cadena de bloques. La obra consta de cuatro bloques plenamente diferenciables, con un total de diez capítulos independientes. A continuación mencionaremos, de manera somera, a cada uno de ellos, formulando las apreciaciones que procedan. Antes de entrar en materia propiamente dicha, cabe señalar unas breves anotaciones, a propósito del prólogo de la obra. En palabras del prologuista, Pedreña Muñoz, la inteligencia artificial, el internet de las cosas y la cadena de bloques generarán una importante convulsión en los actuales sistemas económicos.

Los países, sectores, empresas, consumidores y usuarios que se posicionen correctamente, ostentarán prerrogativas ciertamente notables, mientras que los más conservadores quizás eludan riesgos, pero, naturalmente, serán más dependientes. Tanto Bitcoin como Blockchain se sitúan en la revolución de la innovación abierta, pero también de la economía colaborativa.

Si nos remontamos unos meses atrás, debemos detenernos en lo que aconteció el viernes 12 de mayo de 2017, día en que todos los medios de comunicación del mundo abrían con información de WannaCry. Aunque algunos no recuerden tal nombre, cabe precisar que es un ransomware global que afectó a más de 230000 equipos informáticos en todo el mundo. Los individuos que estaban tras dicha infección informática exigían un rescate de 300 dólares en bitcóins a cambio de descifrar los archivos.

Para la mayoría de la población representaba una de las primeras citas públicas de esta forma de pago virtual. Así, un sector de la población la catalogaba inmediatamente como la moneda de cambio en la Deep Web o web profunda, asociándola con la ciberdelincuencia, el tráfico de armas y demás negocios ilícitos. La web profunda u oculta se erige en un territorio inaccesible de Internet en virtud de buscadores como Google, Bing o Yahoo, entre otros, ya que sus páginas no suelen encontrarse registrados en servidores DNS. Se considera que la Internet oculta constituye el $95 \%$ de la información presente en Internet, y está formada por numerosos sitios privados y peer-to-peer, inscritos con extensiones .onion a los que únicamente puede accederse con direcciones o contraseñas específicas, empleando determinados navegadores como Tor, I2P y Freenet.

Esto último no es del todo riguroso ni se encuentra ajustado a la realidad. En efecto, el bitcoin es extraordinariamente volátil, se erige en una moneda virtual a la que se ha recurrido en múltiples tipologías de negocios de todo el mundo (inmobiliario, alimentación, bancario y un largo etcétera). Si bien bitcoin ha perdido más del $80 \%$ de su valor desde 2017 -repárese en que llegó a los 20000 dólares-, el mercado inmobiliario no se ha dejado 
sacudir por estas férreas caídas. El año en que la mencionada criptomoneda alcanzó su máximo histórico, la venta de bienes raíces utilizando bitcoin se hizo cada vez más popular.

El mercado inmobiliario, con carácter general y en un sentido amplio -casas, apartamentos, residencias de lujo y terrenos-, está siendo negociado, en estos momentos, con criptomonedas, sin que haya incidido de manera notable el prolongado mercado bajista que afecta a este fenómeno desde 2018.

La sociedad global ha comenzado a desmarcarse de la actividad financiera que se plantea a la sombra del bitcoin para centrarse en las oportunidades y el potencial de la cadena de bloques, es decir, la tecnología que sirve de apoyo a la moneda virtual. Efectivamente, los hechos ponen de manifiesto que la cadena de bloques tiene un futuro prometedor.

En tiempos recientes han sucedido eventos de notable interés que no deben de pasar desapercibidos. En 2017 tienen lugar dos grandes acontecimientos: el crecimiento exponencial de Ethereum, uno de los principales rivales de bitcoin, y el recurso masivo y frecuente de las ICOs (Ofertas Iniciales de Monedas) como opción alternativa al capital de riesgo tradicional para la financiación de las denominadas startups. Dentro de estas últimas, encontramos las que en el argot coloquial se denominan unicornios; si bien este término hace alusión a un animal mitológico, en los negocios tiene una connotación muy distinta, al referir a una compañía tecnológica que alcanza un valor de 1000 millones de dólares en alguna de las fases de su proceso de levantamiento de capital. Si tuviéramos que dar algunas características de estas sugerentes empresas, podríamos mencionar un abundante número.

En este sentido, podemos decir que las empresas unicornio surgieron en la era de las redes sociales, y fueron capaces de valerse de su auge para crecer y, posteriormente, consolidarse. Son empresas que, asimismo, hacen uso del modelo B2C, en otros términos, desarrollan una estrategia comercial para llegar directamente al cliente o consumidor final.

Entrando de lleno a la obra, la primera sección consta de dos capítulos. En el primero se abordan los fundamentos informáticos y técnicos del Blockchain. Las bases que se incluyen en este capítulo permitirán comprender los aspectos de índole legal, tecnológico y tributario; además se estudian, entre otras cuestiones, los aspectos generales de la cadena de bloques (código abierto, tokens y criptodivisas, redes públicas o autorizadas, nodos mineros y monederos) y se abordan las particularidades del modelo de Bitcoin, prestando atención a los conceptos elementales de la criptografía, la estructura de la cadena de bloques y el funcionamiento de la red Blockchain. Seguido de esto, se acomete el examen de cuestiones especialmente sugerentes, dentro delas que podemos referirnos a las criptodivisas alternativas -Namecoin; Litecoin; y Peercoin-, a las plataformas Blockchain 2.0 -entre las que destacan Ethereum, Cardano, IOTA, NEO, y NEM- e Hyperledger como paradigma de cadena de bloques privada.

Este primer capítulo concluye con las numerosas prerrogativas de la cadena de bloques, entre las cuales podemos referirnos, sin ánimo agotador, a la desintermediación de procesos, la descentralización total de la información, la transparencia en lo público, la 
privacidad en la protección de datos y la reducción de costes en determinados aspectos de las tecnologías del tratamiento de la información. El segundo capítulo de la primera sección se refiere al Internet del valor, y se profundiza en la cadena de bloques como el Internet del valor que está dando paso al Internet de los pagos. Cada vez, en mayor medida, el valor será la esencia de los nuevos negocios que, progresivamente, se van separando de la dependencia de los activos físicos.

Especialmente sugerente resulta el análisis de los contratos inteligentes. Por decirlo de alguna manera, el Internet del valor se erige en una red modulada por las personas creando contenido sin intermediarios, donde, a su vez, los propios usuarios son tanto emisores como receptores. Las cadenas de bloques que imperan en la actualidad pueden ser públicas -en el supuesto de que estén abiertas a cualquiera que quiera participar de ellas- o privadas -en el caso de que solo algunos puedan intervenir-.

El primer paradigma de cadena de bloques pública es el Bitcoin, creado en 2009 por Satoshi Nakamoto (de identidad desconocida, siendo tal denominación un seudónimo). Tanto en un caso como en otro (público y privado) no es necesaria la participación de una entidad central que haga las tareas de supervisora o autorice los procesos y contenidos. En absoluto; uno de los caracteres inherentes es la descentralización. La cadena de bloques tiene un gran número de prerrogativas; de hecho, entre las mismas, podemos señalar qué hará innecesarios a determinada tipología de terceros para que dos partes puedan realizar una transacción.

Esta afirmación resulta extrapolable, entre otros actores, a Bancos, notarios, auditores, sociedades de autor, o, incluso, intermediarias de pago como Paypal. Para ello, armoniza la tecnología P2P de intercambio entre pares - peer to peer- con la criptografía cifrado de datos-. En definitiva, la cadena de bloques permite que dos peer (iguales) puedan comerciar valor sin necesidad de doble gasto en el intercambio, y, por consiguiente, capturando este valor.

Los aspectos mercantiles y tributarios son objeto de examen en la siguiente sección, que abarca tres capítulos. En el primero de ellos se analizan las particularidades que plantea la cadena de bloques como registro y se examinan el funcionamiento tanto de los DNS sistema de nombres de dominio- como de las ICANN que, como es sabido, se erige en una gestora de nombres. La cadena de bloques plantea numerosos dilemas; uno de ellos es su uso como registro con ciertos efectos jurídicos, donde las anotaciones en este resultan irreversibles. Todo ello hace que la información introducida en la misma no pueda ser alterada a posteriori, pues su descentralización haría posible que cualquier alteración de un dato sea detectada por toda la Red; repárese en que todos los que intervienen en la cadena de bloques tienen la misma información.

El segundo capítulo tiene como fin examinar los aspectos mercantiles de las criptomonedas; asimismo, analizan las diversas modalidades de tokens que imperan: utility tokens, tokens security y equity tokens. Se considera que las criptomonedas constituyen criptoactivos multifunción susceptibles de ser empleados como medio de pago que, en virtud del Art. 1170 del Código Civil español, tiene poder liberatorio. En el último capítulo de esta 
segunda sección se tratan los aspectos contables y tributarios; como que las criptomonedas también están sometidas al abono de impuestos nacionales (Impuesto del Valor Añadido, Impuesto sobre la Renta de las Personas Físicas, Impuesto de Actividades Económicas).

En el caso concreto de España, los usuarios tendrán que informar a la Hacienda Pública de todas las operaciones y los saldos de criptomonedas, tanto en España como en el extranjero; una actuación con la que, dicho sea de paso, se pretende soslayar la elusión de impuestos escondiendo patrimonio a las autoridades fiscales.

La sección tercera de la monografía trata sobre los aspectos empresariales, organizativos y contables de la cadena de bloques. El desarrollo que los diversos Estados están protagonizando se encuentra vinculado con el emprendimiento; los países que incentivan este son los que ostentan tasas de crecimiento más altas. Vinculado con cuanto se expone, no cabe duda que la tecnología está muy relacionada con la actividad del emprendimiento. En esta línea, un aspecto obvio, pero también muy significativo, es que la cadena de bloques está generando un infinito campo de oportunidades de negocio que, hasta hace relativamente poco, eran inimaginables. La cadena de bloques constituye una herramienta de carácter disruptivo, que modifica, por completo, el mundo de los negocios. Si bien es cierto que, si se nos permite el símil, no es el Santo Grial, está en condiciones de modificar los parámetros decimonónicos de la industria.

Como se adelantó previamente, es una base de datos descentralizada, con procedimientos almacenados, particularidades que ya estaban implementadas desde hace años. En los últimos capítulos de esta sugerente sección se abordan la contabilidad de triple entrada y las implicaciones que plantea la cadena de bloques. Esta última, entre otras cosas, permite: instrumentos de información, verificación y transparencia. Es conveniente alcanzar una armonización internacional en virtud de la cual se implementen unos estándares y un marco normativo que hagan posible la aplicación de las plataformas Blockchain y la interoperabilidad de las mismas.

Como acertadamente disponen los autores de este último capítulo, la protección de inversores y consumidores de los nuevos productos que se están ofreciendo en Internet tendrán que resolverse de manera que no impida el progreso de los desarrollos que plantea la cadena de bloques, que son muy prometedoras para la eficacia en la gestión y en la transparencia de la gestión pública.

La cuarta y última sección de la obra se dedica a las aplicaciones que la cadena de bloques puede ofrecer a la Administración Pública, la identidad digital y la participación ciudadana. Dentro de esta sugerente sección se integran dos capítulos independientes, cuyo contenido es verdaderamente sugerente. Blockchain presenta numerosas prerrogativas para el sector público; dentro de las cuales podemos citar, entre otras, la posibilidad de ser útil para la Hacienda Pública, coadyuvando a prevenir el fraude y el blanqueo de capitales.

En el ámbito de la seguridad, los documentos nacionales de identidad (DNI) deberían progresar hacia una tecnología vinculada con la cadena de bloques que avale los derechos 
fundamentales de los individuos, como, por ejemplo, en procesos electorales. Asimismo, en el caso concreto de la Sanidad, podrían mejorarse las listas de espera y las técnicas de admisión. Puede afirmarse, sin temor a equivocarse, de que estamos ante el momento de que la Administración dé un paso adelante, y, de algún modo, deje de actuar a impulsos de la empresa privada.

En otros términos, es deseable y necesario que el sector público invierta en la cadena de bloques, para no perder su papel dominante en la gestión de información. No hacerlo sería un hándicap que puede evitarse para la sociedad. La incorporación de organismos públicos a iniciativas como, entre otros, el Consorcio Alastria, son una excelente noticia, $y$, en este sentido, debemos manifestar brevemente qué representa este último. Cabe señalar que este se encuentra formado por las principales empresas españolas del sector bancario, telecomunicaciones y energía. Se trata de la primera red nacional estatal que se ha creado en el sistema de la cadena de bloques; es un consorcio sin ánimo de lucro alguno que se dedica al desarrollo de la tecnología de registros distribuidos. De algún modo, tiene todos los elementos preceptivos, para llegar a ser el nuevo ecosistema de intercambio de datos, pues, sin duda alguna, está en condiciones de lograr la transformación digital de los diversos sectores industriales y empresariales.

Estamos en condiciones de reclamar una gestión de los datos más eficiente, más segura y, sobre todo, más social; y Blockchain representa la herramienta idónea para tal fin.

Este artículo es de acceso abierto. Los usuarios pueden leer, descargar, distribuir, imprimir y enlazar al texto completo, siempre y cuando sea sin fines de lucro y se cite la fuente.

\section{CÓMO CITAR ESTE ARTÍCULO:}

López Jiménez, D. (2020). Recensión. Blockchain: aspectos tecnológicos, empresariales y legales. Paakat: Revista de Tecnología y Sociedad 10(18). http://dx.doi.org/10.32870/Pk.a10n18.421

\footnotetext{
* Es doctor (con mención europea) por la Universidad de Sevilla y doctor por la Universidad Rey Juan Carlos. Full Professor en EAE Business School. España.
} 